\title{
Finite element analysis to the multi-layer U-shaped bellows' strength and axial stiffness
}

\author{
Shidong Wen ${ }^{1, a}$, Hehui Wang ${ }^{1, b}$, Guilin Tang ${ }^{2, c}$, Xueyi Yin ${ }^{2, d}$, Meng Gao ${ }^{2, \text { e }}$ \\ ${ }^{1}$ School of Mechanical Power Engineering, East China University of Science and Technology, \\ Shanghai 200237, China; \\ ${ }^{2}$ General Construction Company of CCTEB Group Co.,Ltd, Wuhan, 430064, China. \\ a'wenshidong123@163.com, bhhwang@ecust.edu.cn, 'tgl19771977@163.com, d125147589@qq.c \\ om, ${ }^{\mathrm{e}} 190705299 @ q q . c o m$
}

Keywords: multilayer U-shaped bellows, bellows expansion joint, axial stiffness, ANSYS

\begin{abstract}
The multilayer U-shaped bellows' strenth and axial stiffness are studied by ANSYS finite element analysis. The plane axisymmetric model of multilayer bellows is established, and the material nonlinear, geometric nonlinearity and contact between the layers of multilayer bellows is considered, obtained some useful conclusions. And the analysis results are compared with the results calculated by engineering approximation method, indicating that the ANSYS finite element results closer to the actual situation, there are some errors when using the engineering approximation method analysis multilayer bellows.
\end{abstract}

\section{Introduction}

Multilayer U-shaped expansion joint is nested multilayer shell structure, there are more advantages than the single layer bellows, such as small stiffness, good compensation performance and good pressuring capacity [1]. Due to the complex structure of the multilayer bellows, but also the material nonlinear, large deformation and contact problem, makes the mechanical model of theoretical calculation of great error. With the development of the computer, the finite element method is increasingly becomes the main study method of bellows, it has no limit on the complexity of the model, and can also simulate complex load condition, the material nonlinear, large deformation and contact between the layers, the calculation results are closer to the actual situation. This paper uses the ANSYS FE method, established the model of multilayer bellows, obtained the stress distribution and the axial stiffness value, and compared they with the results calculated by engineering approximation method.

\section{Strenth Analysis}

Geometrical structure. The geometrical structure of multi-layer bellows showns in Fig.1, $D_{b}=473 \mathrm{~mm}, D_{m}=517 \mathrm{~mm}, h=44 \mathrm{~mm}, q=55 \mathrm{~mm}, \delta=1.7 \mathrm{~mm}, n=4$.

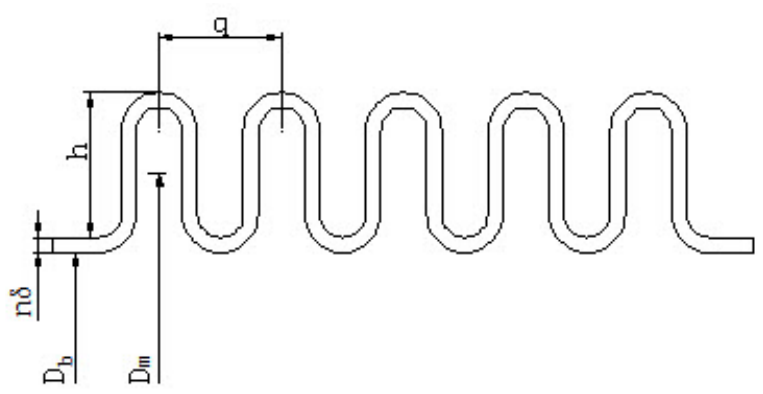

Fig. 1 The geometry of multilayer bellows

Molded material parameters. The material of bellows is 0Cr18Ni9, elasticity modulus $E=1.96 \times 10^{5} \mathrm{Mpa}$, poisson ratio $\rho=0.3$, yield strength $\sigma_{0.2}=206 \mathrm{Mpa}$. The wall thickness 
of molded bellows will thin, the wall thickness of the valley is thinner, and the crest is thicker [2]. According to the standard GB / T-12777-2008-T < General technical requirements of metal bellows expansion joint $>$ [3], the average wall thickness of molded bellows calculate according to formula (1), the yield strength calculation formula of molded bellows calculate according to formula (2).

$$
\begin{aligned}
& \delta_{m}=\delta \sqrt{\frac{D_{b}}{D_{m}}} \\
& \sigma_{0.2 y}=0.67 C_{m} \sigma_{0.2}
\end{aligned}
$$

$C_{m}$ is the strength coefficient of bellows material, looking-up table get $C_{m}=1.59$ [3], calculated $\delta_{m}=1.53 \mathrm{~mm}, \sigma_{0.2 y}=328 \mathrm{Mpa}$.

Table 1 Molded material parameters

\begin{tabular}{cccc}
\hline $\begin{array}{c}\text { Yield stress } \\
\text { /Mpa }\end{array}$ & $\begin{array}{c}\text { elasticity modulus } \\
\text { /Gpa }\end{array}$ & $\begin{array}{c}\text { Plastic modulus } \\
\text { /Mpa }\end{array}$ & $\begin{array}{c}\text { Poisson } \\
\text { ratio }\end{array}$ \\
\hline 328 & 196 & 3640 & 0.3 \\
\hline
\end{tabular}

FE model. With axisymmetric geometrical structure and symmetrical load, the plane axisymmetric model of bellows was established, the meshed model of multilayer bellows showns in Fig. 2.

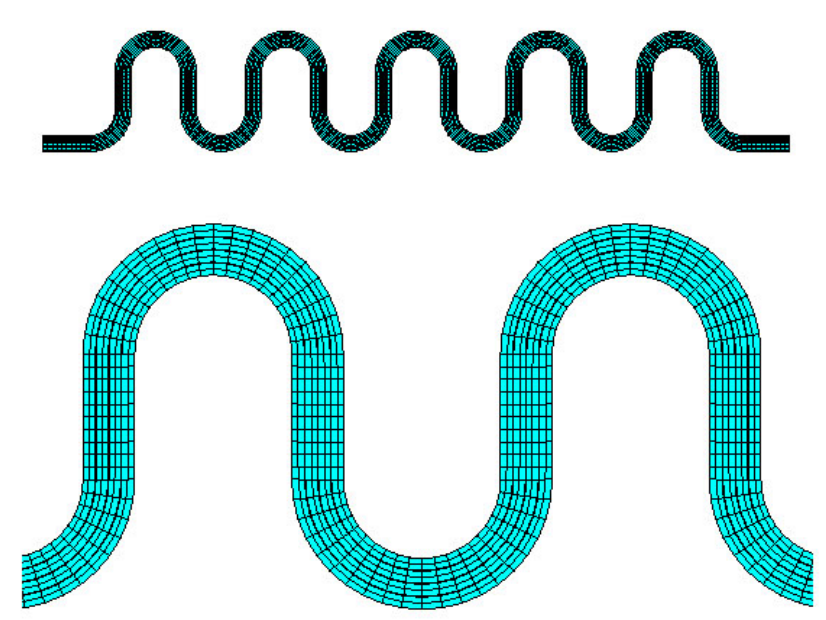

Fig. 2 The meshed modol of multilayer bellows

Using TARGET169 element and CONTAl72 element built the contact pair, set friction coefficient of 0.12 , contact stiffness factor of 1.0, and interlayer spacing of $0.1 \mathrm{~mm}[4]$ 。

Set fixed constraint on the one end of bellows, set axial compressive displacement $S_{y}=-17 \mathrm{~mm}$ on the other end, and pressure $P=3.5 \mathrm{Mpa}$ on the internal face.

Result analysis. The stress intensity distribution is showns Fig. 4. The maximum stress is located in the outermost layer of first valley from the fixed end, where the curvature radius is minimum and constraint biggest. 


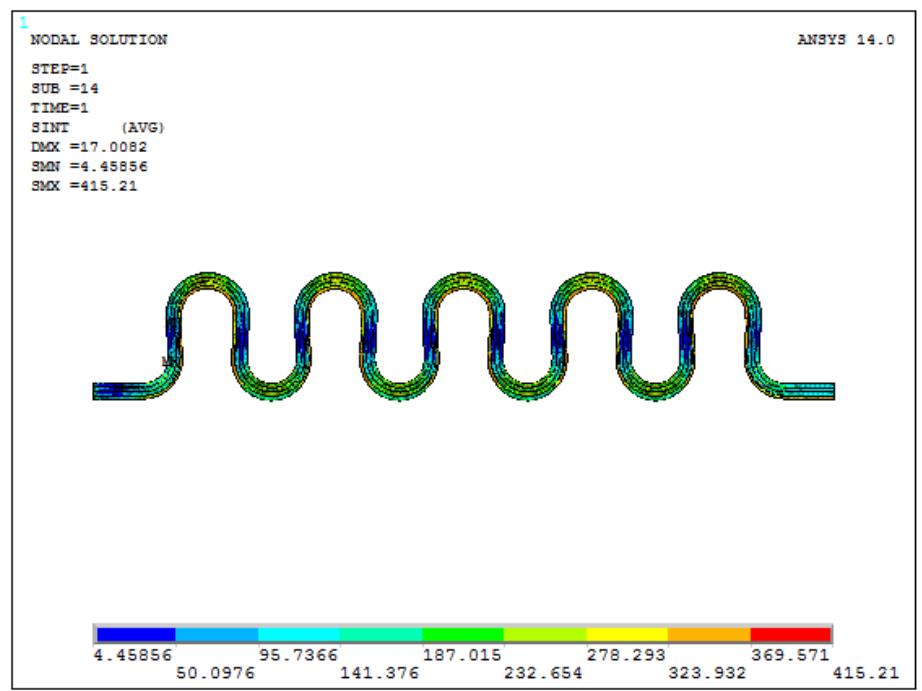

Fig.3 Stress intensity distribution of bellows

The node stress intensity distribution of each layer along the first wave is showns in Fig. 4.

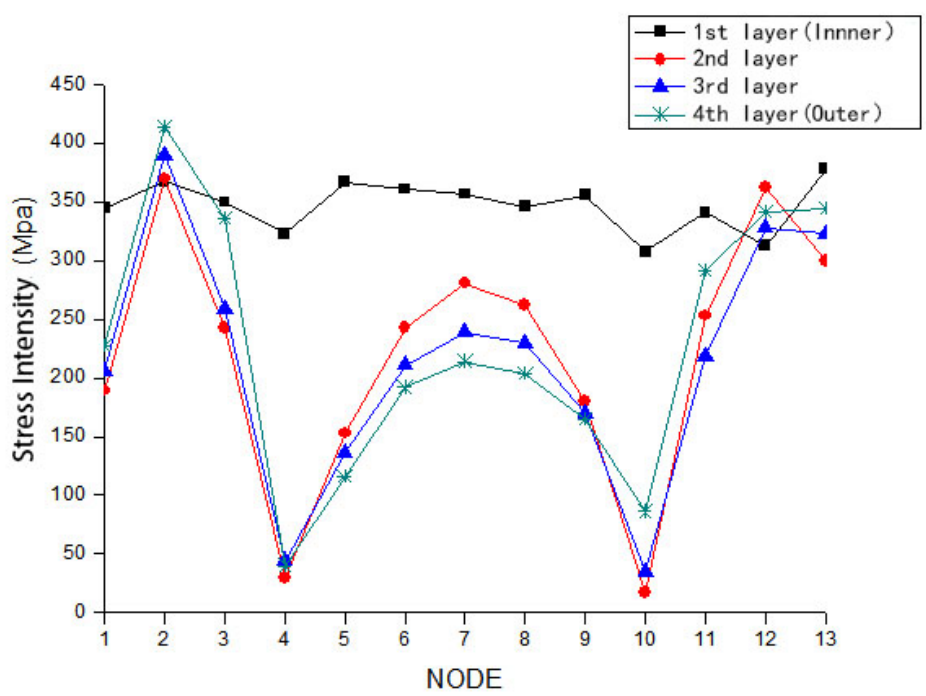

Fig. 4 The stress intensity along first wave

Fig.4 illustrates that the stress distribution law is very close of layer 2 to layer 4, the stress intensity of vally is maximum, followed by wave location, stress of ring plate location close to zero.

Compared with the theoretical results. With the formula from T-12777-2008-T < General technical requirements of metal bellows expansion joint $>[3]$, various stress under internal pressure load or displacement load are got in Table 2.

Table 2 Various stress comparation

\begin{tabular}{ccccl}
\hline & $\begin{array}{c}\text { Stress } \\
\text { type }\end{array}$ & $\begin{array}{c}\text { theoretical results } \\
\text { /Mpa }\end{array}$ & $\begin{array}{c}\text { FEM results } \\
\text { /Mpa }\end{array}$ & Error \\
\hline \multirow{4}{*}{ Pressure Load } & $\sigma_{1}$ & 62.5 & 89 & $29.8 \%$ \\
& $\sigma_{2}$ & 86.8 & 95 & $8.6 \%$ \\
& $\sigma_{3}$ & 11.8 & 40 & $70 \%{ }^{\text {note1 }}$ \\
& $\sigma_{4}$ & 207 & 240 & $13.8 \%$ \\
\hline \multirow{2}{*}{$\begin{array}{c}\text { Displacement } \\
\text { Load }\end{array}$} & $\sigma_{5}$ & 15 & 41 & $63.4 \%{ }^{\text {note1 }}$ \\
& $\sigma_{6}$ & 447 & 344 & $23 \%$ \\
\hline
\end{tabular}

Note 1: The error of the meridional direction membrane stress is maximum, it's because the results of theoretical formula is based on the ring plate location, and the results of FEM is based on the vally location. 
$\sigma_{1}$ - peripheral direction membrane stress of bellows straight flange; $\sigma_{2}$ - peripheral direction membrane stress of bellows; $\sigma_{3}, \sigma_{5}$ - meridional direction membrane stress of bellows; $\sigma_{4}, \sigma_{6}$ meridional direction bending stress of bellows.

As can be seen from Table 2 for stresses caused by internal pressure, the theoretical calculation results smaller than the FE method results, however, the meridional direction bending stress of bellows caused by displacement, the theoretical calculation result is greater than the FE method result. This is mainly because that the theoretical calculation method use the same thickness of single-layer bellows approximate multi-layer bellows, and the FE method considering interlayer contact effect.

\section{Stiffness Analysis}

The axial stiffness of bellows is a significant performance parameter, stiffness is too small, bellows may produce excessive deformation and occur instability, stiffness is too large, bellows will be difficult to meet the requirements of displacement compensation [5].

EJMA calculation. The standard of the expansion joint manufacturers association [6], gives the stiffness calculation formula of multi-layer bellows that combinated with the engineering practice and consider the correction coefficient. Correction coefficient $C_{f}=1.45$, get $K_{n}=3996 \mathrm{~N} / \mathrm{mm}$.

$$
K_{n}=\frac{1.7 D_{m} E_{b}^{t} \delta_{m}^{3} n}{h^{3} C_{f} N}
$$

FE method calculation. Establish the FE model, set fixed constraint on the one end of bellows, apply uniformly distributed pressure load on the other end. The axial stiffness calculation formula of bellows is as follows.

$K^{\prime}=F / S$

$F$ - the axial force; $S$ - the axial displacement. The axial displacement of multi-layer bellows generated under different loads calculated by ANSYS are as follow.

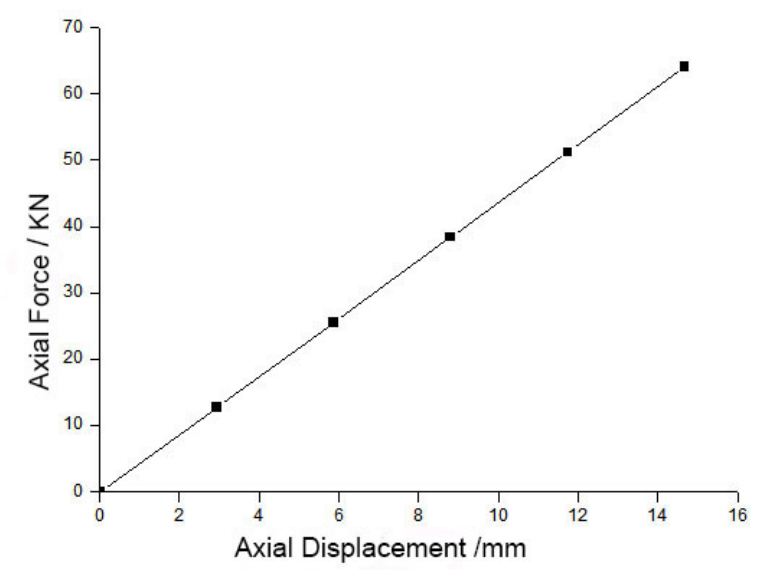

Fig. 5 The relationship of axial displacement and axial force

Calculated the axial stiffness is $4361 \mathrm{~N} / \mathrm{mm}$, the relative error with the result of EJMA is $8.4 \%$.

\section{Summary}

The theoretical calculation results of multi-layer bellows may not always be safe, the FE method consider the material nonlinear, large deformation and contact between the layers, the calculation results are closer to the actual situation.

The stress distribution of the inner layer and outer layers have significant difference. Because of the interlayer effect, the inner layer beared a large force, and the force transfered to the outer layers is already very small.

The stress distribution regularity of external layers are very similar. The stress of vally location is maximum, followed by wave location, stress of ring plate location close to zero. 
The error of axial stiffness of multi-layer bellows calcualted by EJMA method and by FE method is very small.

\section{References}

[1] Wang Yang, Research on strength, stiffness and buckling analysis of multilayer bellows, D: Nanjing University of Aeronautics and Astronautics, 2005.

[2] Liu Chuang, The steam hammer failure analysis and calculation for the large expansion joint of the styrene project, D: East China University of Science and Technology, 2013.

[3] GB/T 12777-2008 General technical requirements of metal bellows expansion joint, 2008.

[4] Li Jie, Duan Mei, Analysis on contact and stable squirm of multi-ply bellows, J. Development and Application of Materials. 163 (2011) 57-61.

[5] Ren Ning, Ou Kai-Liang, Research on the axial stiffness of $\Omega$-shaped bellows, J. Mechanical Strength, 5 (2011) 91-95.

[6] Standards of the expantion joint manufacturers association (EJMA), S. EJMA, INC, Seven ed., New york, 1998. 